\title{
Pericardite constritiva em transplantado renal
}

\section{Constrictive pericarditis after renal transplantation}

\author{
Isabela Rodrigues Brandãoํ․ Rochelle Pinheiro Ribeiro ${ }^{2}$. \\ 1 Residente em Clínica Médica, Hospital Universitário Walter Cantídio (HUWC), Universidade Federal do Ceará (UFC), Fortaleza, \\ Ceará, Brasil. 2 Mestre em Saúde Pública pela Universidade Federal do Ceará (UFC), Cardiologista pelo Hospital Universitário \\ Walter Cantídio (HUWC), Fortaleza, Ceará, Brasil.
}

\section{RESUMO}

O pericárdio é a membrana que envolve o coração. Quando ele se torna rígido, semelhante a uma carapaça, e isso pode acontecer por diversas causas, ele passa a constringir o órgão, prejudicando seu bom funcionamento. Isto causa sinais e sintomas característicos de insuficiência cardíaca. O objetivo deste relato é mostrar um caso de pericardite constritiva provavelmente idiopática submetido a pericardiectomia, cuja clínica de ascite, edema de membros inferiores e turgência jugular, refratária ao uso de diuréticos, se iniciou sete meses após a realização de transplante renal, quando em uso de tacrolimo e micofenolato de mofetila. Os dados foram coletados por meio de revisão de prontuário.

Palavras-chave: Pericardite. Transplante renal. Cardiomiopatia restritiva.

\section{ABSTRACT}

The pericardium is the membrane that surrounds the heart. When it becomes thick, similar to a carapace, and it can happen for various reasons, it begins to constrict the organ, impairing its proper functioning. This causes signs and symptoms characteristics of heart failure. The aim of this report is to show a case of probably idiopathic constrictive pericarditis submitted to pericardiectomy, whose clinics of ascitis, lower limb edema and jugular turgor, refractory to the use of diuretic drugs, started seven months after renal transplantation, when taking tacrolimus and mycophenolate mofetil. Data were collected through a review of medical records.

Keywords: Pericarditis. Kidney transplantation. Restrictive cardiomyopathy.

Autor correspondente: Isabela Rodrigues Brandão, Rua General Tertuliano Potiguara, 1199, apartamento 2001, Aldeota, Fortaleza, Ceará. CEP: 60135-280. Telefone: +55 85 99995-1097. E-mail: isabelabrandao@gmail.com

Conflito de interesses: Não há qualquer conflito de interesses por parte de qualquer um dos autores.

Recebido em: 19 Fev 2017; Revisado em: 24 Set 2017; Aceito em: 29 Out 2017. 


\section{INTRODUÇÃO}

A pericardite constritiva (PC) é caracterizada pelo aprisionamento do coração por um pericárdio rígido devido a fibroses e adesões densas. Isto acaba por causar disfunção cardíaca diastólica, levando a insuficiência cardíaca. ${ }^{1}$ É frequentemente confundida com outros diagnósticos, tais como hepatopatia crônica, cardiomiopatia restritiva e cardiopatia idiopática. ${ }^{2}$ Identificar a etiologia da PC é muito difícil. Causas incluem tuberculose, colagenoses, uremia, febre reumática, radioterapia, neoplasias, cirurgia cardíaca prévia ou idiopática. A tuberculose é uma causa clássica de PC, mais frequente em regiões endêmicas. ${ }^{3}$ A pericardiectomia apresenta um impacto favorável na história natural desta entidade, conduzindo a uma melhora sintomática em $90 \%$ dos casos e a um alívio completo em $50 \%$. $^{3} \mathrm{O}$ objetivo deste estudo é relatar um caso de pericardite constritiva de causa idiopática submetido a pericardiectomia.

\section{RELATO DO CASO}

Paciente masculino, 50 anos, pardo, radialista, admitido no Serviço de Cardiologia do Hospital Universitário Walter Cantídio em janeiro de 2015 por ascite, edema de membros inferiores e ortopneia havia seis meses, tendo necessitado de paracenteses repetidas por desconforto respiratório. Tinha história de transplante renal havia doze meses, após perda súbita da função renal por causa ignorada, e fizera terapia dialítica por quinze anos. Estava em uso de tacrolimus e micofenolato mofetil. As análises do líquido ascítico mostravam padrão de exsudato.

À admissão, apresentava-se em regular estado geral, levemente ictérico, eupneico, normocorado, orientado, com turgência jugular bilateralmente. À ausculta cardiopulmonar, ritmo cardíaco regular, bulhas normofonéticas, sem sopros, com knock pericárdico, e murmúrio vesicular presente, reduzido em bases, sem ruídos adventícios. Exame abdominal revelou abdome globoso por ascite com teste do piparote positivo, indolor, sem visceromegalias ou massas, ruídos hidroaéreos presentes, espaço de Traube timpânico. Pulsos periféricos cheios e presentes, com edema de membros inferiores e fístulas arteriovenosas em ambos membros superiores, uma delas inativa.

Realizou teste tuberculínico, que se mostrou reator forte (PPD $11 \mathrm{~mm})$, e ecocardiograma transtorácico, com fração de ejeção $67 \%$, aumento dos átrios, pericárdio espessado, mínimo derrame e disfunção diastólica tipo III. Estudo histopatológico de fragmento pericárdico foi compatível com pericardite inespecífica sem sinais de malignidade. Apresentava clearance de creatinina de $46 \mathrm{ml} / \mathrm{min} / 1,73 \mathrm{~m}^{2}$ e ureia de 57 à admissão, o que afastou a hipótese de pericardite urêmica.

Foi submetido a terapia diurética com furosemida e espironolactona e esquema RIPE, caracterizado pelo esquema atual de tratamento de tuberculose, composto por rifampicina, isoniazida, pirazinamida e etambutol. Não apresentou melhora clínica, sendo realizada ressonância magnética $(\mathrm{RM})$ do coração, que mostrou dilatação biatrial importante, ventrículos com dimensões preservadas, função biventricular sistólica preservada, pericárdio irregular, com sinais de espessamento difuso, mais evidente junto à parede livre do ventrículo esquerdo, com espessura máxima de $6 \mathrm{~mm}$, apresentando realce tardio ao meio de contraste compatível com fibrose e ausência de fibrose miocárdica, todos estes achados compatíveis com pericardite constritiva (Figura 1).

Figure 1. Imagem de ressonância magnética do coração mostrando as quatro cavidades cardíacas e espessamento do pericárdio, especialmente próximo ao ventrículo direito.

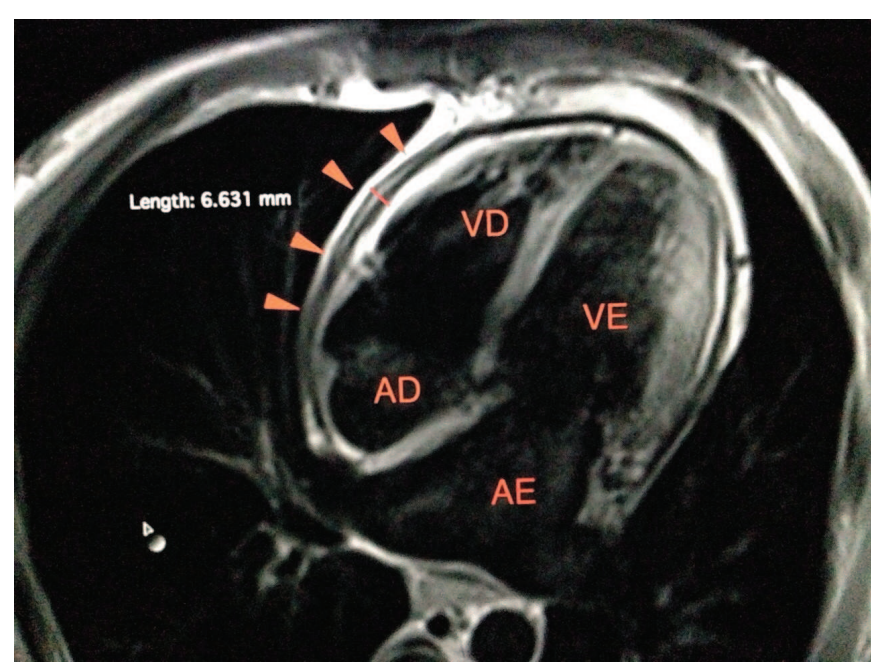

A pericardiectomia foi realizada três meses após a admissão. No transoperatório, foi encontrado um pericárdio espessado, firmemente aderido ao epicárdio. O ecocardiograma pós-cirúrgico mostrou fração de ejeção de $80 \%$, insuficiência tricúspide de grau leve, aumento das dimensões dos átrios, veia cava inferior túrgida, com pouca variação à respiração, com presença de fisiologia constritiva. No pós-operatório imediato, evoluiu com acidose metabólica e aumento persistente das escórias nitrogenadas, com necessidade de hemodiálise, e persistência da ascite. Após realização de pulso com metilprednisolona, foi decretada perda do enxerto renal dois meses após a cirurgia. Estudo histopatológico do pericárdio mostrou pericardite crônica inespecífica, moderadamente fibrosante, não permitindo definição etiológica.

\section{DISCUSSÃO}

Apresentamos este caso por haver pontos de especial interesse, como a associação à doença renal crônica e a etiologia obscura. Nesse caso, chama a atenção a intensidade do espessamento pericárdico, que chegava ao ponto de provocar a clínica de edema associado a ascite e desconforto respiratório. $\mathrm{Na}$ literatura, há escassez de trabalhos acerca de pericardite constritiva.

A PC é uma doença caracterizada pelo aprisionamento do coração por um pericárdio rígido, não dobrável, devido a fibroses e adesões densas ${ }^{1}$ que habitualmente começa com um 
episódio inicial de pericardite aguda, seguido por um estágio crônico, caracterizado por cicatrização fibrosa e espessamento do pericárdio com obliteração do espaço pericárdico. $\mathrm{Na}$ maioria dos casos, as camadas visceral e parietal tornam-se completamente fundidas. ${ }^{2}$ Normalmente, o pericárdio apresenta uma espessura de $3 \mathrm{~mm}$. Na constrição crônica, especialmente a de etiologia tuberculosa, pode ultrapassar $10 \mathrm{~mm}$. Isto acaba por causar disfunção do coração levando a insuficiência cardíaca, sendo as alterações resultantes de um pericárdio não distensível caracterizadas por disfunção diastólica dos ventrículos e dissociação entre as pressões intracardíaca e intratorácica durante a respiração. Por vezes, pode-se encontrar o knock pericárdico (correspondendo à rápida desaceleração do enchimento ventricular). Como consequência da congestão hepática, é frequente existirem aranhas vasculares, icterícia, eritema palmar, hepatomegalia e ascite. ${ }^{3}$ Edema periférico e hipoalbuminemia são achados também frequentes. ${ }^{2}$

A ascite na PC é desproporcional e ocorre geralmente antes do aparecimento do edema periférico, sequência oposta à que ocorre nas cardiopatias congestivas. Derrames pleurais estão presentes em $60 \%$ dos pacientes. É frequentemente confundida com outros diagnósticos, tais como hepatopatia crônica, cardiomiopatia restritiva e cardiopatia idiopática. ${ }^{2}$

A tuberculose é uma causa clássica de PC. As pericardites constritivas idiopáticas continuam frequentes e são, talvez, pós-infecciosas. ${ }^{2,4}$ Embora a prevalência da tuberculose tenha vindo a diminuir nos últimos anos nos países desenvolvidos, continua a ser a principal causa de pericardite nos países em desenvolvimento. $^{3}$

Dentre causas não tuberculosas, destacam-se cirurgia cardiovascular, radioterapia, neoplasias (pulmão, mama, linfoma de Hodgkin), doenças do tecido conjuntivo (artrite reumatoide, lupus eritematoso sistêmico) e, mais raramente, outras infecções (bacterianas, fúngicas, parasitárias), insuficiência renal crônica em hemodiálise, pericardite pós-infarto agudo do miocárdio, entre outras. ${ }^{3,5} \mathrm{~A}$ PC é uma doença progressiva, sem reversão espontânea do espessamento pericárdico. ${ }^{2}$

Os achados eletrocardiográficos são a baixa voltagem dos complexos QRS. A tomografia e RM cardíacas, esta com maior sensibilidade, permitem identificar o espessamento e as calcificações do pericárdio. Esta é útil no diagnóstico precoce da pericardite constritiva, apresentando como vantagem à TC permitir detectar pequenos espessamentos pericárdicos. ${ }^{3}$

O diagnóstico é suspeitado a partir da clínica, da radiografia simples de tórax, da eletrocardiografia (ECG) e do ecocardiograma. A RM é um exame morfofuncional que, de maneira resumida, mostra um espessamento do pericárdio e anomalias dinâmicas relacionadas a disfunção diastólica. ${ }^{2,4}$ Nesse contexto, é exame de qualidade inegável para o diagnóstico de calcificações e para o planejamento pré-operatório em razão da possibilidade de reconstruções volumétricas particularmente úteis ao cirurgião. ${ }^{4}$
Em alguns países da África e da Ásia, a pericardite tuberculosa (PT) é a causa mais frequente de pericardite. A PT é mais comum entre a terceira e a quinta década de vida, e três a quatro vezes mais frequente em homens. A pericardite constritiva, por sua vez, representa uma das sequelas mais graves da PT, apresentando-se em 30 a $60 \%$ dos pacientes, na maioria em sua forma subaguda. ${ }^{6}$ É primordial que um tratamento adequado seja instituído de maneira precoce. A biópsia pericárdica deve ser contemplada para uma visão diagnóstica quando nenhuma etiologia pôde ser identificada em três semanas de evolução de uma pericardite, sendo menos tempo em zona não-endêmica. Em zonas endêmicas, a biópsia não é necessária para iniciar o tratamento se nenhuma causa evidente para o derrame for encontrada. $^{?}$

O tratamento da PC é a pericardiectomia. Em alguns pacientes, a função cardíaca não é restaurada logo após a cirurgia, podendo levar algum tempo até a normalização. ${ }^{2}$ No caso de PT, a terapêutica antibacilar deve ser iniciada 2 a 4 semanas antes da cirurgia e prolongada até 6 a 12 meses depois. $^{3}$ Os esquemas de tratamento da PT preconizam uso de rifampicina, isoniaziada, pirazinamida e etambutol por dois meses, seguidos de isoniazida e rifampicina por quatro meses para, assim, completar um período total de tratamento de seis meses. ${ }^{6,7}$ Um número significativo de doentes mantém alterações da função diastólica, as quais se correlacionam diretamente com as manifestações clínicas e tendem a ocorrer em doentes com um quadro clínico pré-operatório de longa evolução. É necessário efetuar a pericardiectomia o mais precocemente possível nos doentes com doença sintomática. ${ }^{3}$

Estudo de 2004 que avaliou 163 pacientes submetidos a pericardiectomia por PC de 1977 a 2000 mostrou que esta era idiopática ou viral em 75 pacientes (46\%), pós-cirurgia cardíaca em 60 , secundária a irradiação mediastinal prévia em 15 e de causas variadas em 13 pacientes. Causas variadas de PC foram tuberculose, artrite reumatoide, lúpus eritematoso sistêmico, trauma torácico prévio, granulomatose de Wegener e pericardite purulenta. Este estudo é uma das maiores séries atuais determinando sobrevivência após pericardiectomia para PC. Resultados demonstram que a etiologia tem um impacto importante na sobrevivência a longo prazo, que foi excelente nos grupos de PC idiopática e no grupo de causas variadas. Vê-se que a sobrevida global pós-cirurgia difere significantemente entre os principais subgrupos etiológicos e é melhor para pacientes com constrição idiopática ou de causas variadas. Usando parâmetros como função sistólica de ventrículo esquerdo, sódio sérico, pressão sistólica da artéria pulmonar e creatinina, é possível predizer o grau de sobrevivência a longo prazo pós-pericardiectomia. A excelente sobrevivência pós-cirurgia para PC idiopática realça o fato de que, enquanto entidade isolada, a constrição pericárdica pode ser tratada com segurança com cirurgia. ${ }^{1}$

A pericardiectomia apresenta um impacto favorável na história natural da PC, conduzindo a uma melhoria sintomática em $90 \%$ dos casos e a um alívio completo em 50\%. Tem uma mortalidade operatória baixa, embora possa atingir os 5 a 15 $\%$ nos casos mais avançados. ${ }^{3}$ 
Entendemos que a PC é uma forma rara de doença restritiva cardíaca e, assim, deve ser colocada no rol de diagnósticos diferenciais deste tipo de miocardiopatia. É importante frisar que, aqui, o tecido miocárdico encontra-se em perfeitas condições, estando esta moléstia, entretanto, confinada ao tecido pericárdico. É de suma importância que seja feito o diagnóstico correto em tempo hábil. No caso deste paciente,

\section{REFERÊNCIAS}

1. Bertog SC, Thambidorai SK, Parakh K, Schoenhagen P, Ozduran V, Houghtaling PL, et al. Constrictive pericarditis: etiology and cause-specific survival after pericardiectomy. J Am Coll Cardiol. 2004;43(8):1445-52.

2. Godoy MF, De Francischi FB, Pavarino PR, Oliveira MA, Soares MJ, Braile DM. Forma inusitada de pericardite crônica constritiva idiopática. Braz J Cardiovasc Surg. 2007;22(1):1-6.

3. Marta MJ, Oliveira A, Varela MG, Saavedra JA, Ravara L. Pericardite tuberculosa constritiva: caso clínico e revisão da literatura. Rev Port Cardiol. 2003;22(3):391-405. houve uma certa demora na feitura do diagnóstico correto e na programação cirúrgica, uma vez que a RM cardíaca, que é importante ao diferenciar doença miocárdica de pericárdica, ainda é realizada em poucos centros no Ceará e tem alto custo. Cabe salientar que este exame foi pago com recursos provenientes dos médicos assistentes, residentes e internos que conduziram o caso à época de sua internação.

4. Dacher JN, Caudron J, Fares J, Germain P. Comment je fais une IRM pour péricardite chronique constrictive? J Radiol. 2010;91(5):623-9.

5. Chacón ER, Alpízar CM, Arias A, Arce CD, Vargas CS. Pericarditis y pericardiectomía: experiencia en el Hospital R. A. Calderón Guardia, 2003-2010. Rev Costarric Cardiol. 2011;13(2):15-19.

6. Tapia EO. Pericarditis constrictiva tuberculosa: reporte de un caso y revisión de la literatura. Int J Morphol. 2012;30(2):696-700.

7. Brondex A, Vanoye C, Grippari JL, Arlès F. La péricardite tuberculeuse: un diagnostic qui reste d'actualité. Ann Cardiol Angeiol (Paris). 2010;59(4):234-7.

\section{Como citar:}

Brandão IR, Ribeiro RP. Pericardite constritiva em transplantado renal. Rev Med UFC. 2018 abr-jun;58(2):55-58. 